\title{
Behavioral and psychosocial effects of rapid genetic counseling and testing in newly diagnosed breast cancer patients: Design of a multicenter randomized clinical trial
}

Marijke R Wevers ${ }^{1,2}$, Margreet GEM Ausems², Senno Verhoef ${ }^{3}$, Eveline MA Bleiker ${ }^{1}$, Daniela EE Hahn ${ }^{4}$, Frans BL Hogervorst ${ }^{3}$, Rob B van der Luijt ${ }^{2}$, Heiddis B Valdimarsdottir ${ }^{5}$, Richard van Hillegersberg ${ }^{6}$, Emiel JTh Rutgers ${ }^{7}$, Neil K Aaronson ${ }^{1 *}$

\begin{abstract}
Background: It has been estimated that between $5 \%$ and $10 \%$ of women diagnosed with breast cancer have a hereditary form of the disease, primarily caused by a BRCA1 or BRCA2 gene mutation. Such women have an increased risk of developing a new primary breast and/or ovarian tumor, and may therefore opt for preventive surgery (e.g., bilateral mastectomy, oophorectomy). It is common practice to offer high-risk patients genetic counseling and DNA testing after their primary treatment, with genetic test results being available within 4-6 months. However, some non-commercial laboratories can currently generate test results within 3 to 6 weeks, and thus make it possible to provide rapid genetic counseling and testing (RGCT) prior to primary treatment. The aim of this study is to determine the effect of RGCT on treatment decisions and on psychosocial health.
\end{abstract}

Methods/Design: In this randomized controlled trial, 255 newly diagnosed breast cancer patients with at least a $10 \%$ risk of carrying a BRCA gene mutation are being recruited from 12 hospitals in the Netherlands. Participants are randomized in a 2:1 ratio to either a RGCT intervention group (the offer of RGCT directly following diagnosis with tests results available before surgical treatment) or to a usual care control group. The primary behavioral outcome is the uptake of direct bilateral mastectomy or delayed prophylactic contralateral mastectomy. Psychosocial outcomes include cancer risk perception, cancer-related worry and distress, health-related quality of life, decisional satisfaction and the perceived need for and use of additional decisional counseling and psychosocial support. Data are collected via medical chart audits and self-report questionnaires administered prior to randomization, and at 6 month and at 12 month follow-up.

Discussion: This trial will provide essential information on the impact of RGCT on the choice of primary surgical treatment among women with breast cancer with an increased risk of hereditary cancer. This study will also provide data on the psychosocial consequences of RGCT and of risk-reducing behavior.

Trial registration: The study is registered at the Netherlands Trial Register (NTR1493) and ClinicalTrials.gov (NCT00783822).

\footnotetext{
* Correspondence: n.aaronson@nki.nl

'Division of Psychosocial Research and Epidemiology, The Netherlands

Cancer Institute, PO Box 90203, 1006 BE Amsterdam, The Netherlands

Full list of author information is available at the end of the article
} 


\section{Background}

\section{Breast cancer and genetics}

Breast cancer is the most frequently occurring malignancy in women in the Netherlands. Approximately 1 in 8 women will develop the disease during their lifetime, resulting in approximately 12,000 new cases annually. A positive family history of breast cancer is the single strongest risk factor for developing the disease. In $5 \%-10 \%$ of the cases, breast cancer has a hereditary basis. In $15 \%-30 \%$ of patients from high-risk families, breast cancer is caused by a germline mutation in the $B R C A 1$ or $B R C A 2$ gene [1-4]. A similar percentage of breast cancers is expected to have a genetic basis due to mutations in (combinations of) other low penetrance breast cancer susceptibility genes [5]. Current estimates indicate that women who carry mutations in the BRCA1 or $B R C A 2$ genes have up to an $85 \%$ lifetime risk of developing breast cancer, and can also have up to a $60 \%$ lifetime risk of developing ovarian cancer [6,7]. Breast cancer patients who carry a $B R C A 1 / 2$ mutation have a $3 \%$ annual risk of developing contralateral breast cancer, with the overall risk being as high as $52 \%$ by the age of $70[7,8]$. For $B R C A 1 / 2$ carriers who were diagnosed with breast cancer before the age of 40 years, the cumulative risk of developing contralateral breast cancer after a follow up of 25 years is even higher, i.e. 63\% [9]. Given these high rates of new primary cancers, breast cancer patients with strong family histories of the disease may benefit from genetic counseling and testing as a means of making a well-informed decision on preventive measures.

\section{Genetic counseling and testing in breast cancer patients}

The objectives of cancer genetic counseling, in general, are to improve knowledge and understanding of the possible genetic basis of the disease, of personal risks of developing cancer, and of the possible consequences of undergoing genetic testing $[10,11]$. In the case of breast cancer, the goal of genetic counseling is to ensure that women have been sufficiently educated regarding inherited breast/ovarian cancer to make informed decisions concerning genetic testing, and available preventive and treatment options $[12,13]$. The majority of published studies have found that genetic counseling is effective in increasing knowledge and awareness of cancer risk, and of the consequences of genetic testing [11,14-16]. Factors that may be indicative of hereditary breast cancer are young age at diagnosis, multiple family members with breast cancer, male relatives with breast cancer, breast and ovarian cancer in the family and/or breast cancer and prostate cancer in family members at a relatively young age. Women with one or more of these factors are considered to have a $10 \%$ risk or greater of carrying a $B R C A 1$ or $B R C A 2$ gene mutation, and are thus, in general, considered as candidates for DNA testing. Genetic counseling and DNA testing for breast cancer usually takes approximately 4-6 months to complete. However, some hospitals and non-commercial laboratories are now able to generate test results within 3 to 6 weeks. This technology of rapid genetic testing creates new opportunities for providing both women and their treating surgeons with information potentially relevant for deciding between available treatment options, including type of surgery and adjuvant therapy [17-19].

Newly diagnosed patients who learn that they are gene mutation carriers may decide to undergo a mastectomy rather than a lumpectomy, or bilateral mastectomy (BLM) rather than unilateral mastectomy. Recent studies have shown that BLM and delayed contralateral prophylactic mastectomy (CPM) substantially reduce the risk of contralateral breast cancer, while studies on survival have yielded mixed results [20-23]. Additionally, women who choose unilateral or bilateral mastectomy as their initial surgical treatment will often be spared the necessity of undergoing radiation therapy. However, rapid genetic counseling and testing (RGCT) may necessitate some delay in surgical treatment until DNA test results are available. Previous studies have indicated that the majority of newly diagnosed breast cancer patients at high risk of being $B R C A 1 / 2$ mutation carriers will accept the invitation to undergo RGCT, and that the DNA test results can have a substantial impact on the choice of surgery $[3,24,25]$. In these British and American studies, between one-half and two-thirds of the breast cancer patients carrying a $B R C A 1$ or $B R C A 2$ mutation opted for a bilateral mastectomy, with some opting for a delayed CPM instead of direct BLM. Additionally, between $16 \%$ and $24 \%$ of high-risk patients who test negative for a BRCA1/2 mutation opted for BLM [3,25].

The psychosocial impact of genetic testing in recently diagnosed breast cancer patients has been the subject of only limited study [26]. Although disclosure of test results may increase short term psychological distress, there is no evidence to suggest that there is a sustained increase in levels of distress as a result of such counseling or testing [26-28]. A Dutch study showed that an active approach to genetic counseling in patients recently diagnosed with breast cancer and in an early stage of primary treatment (i.e. 7-8 weeks after surgery), did not increase psychological stress significantly $[27,28]$. In addition, in a small pilot study in 8 women who were offered RGCT following their breast cancer diagnosis but prior to surgery, none reported that the offer of RGCT had added significantly to the stress that they were already experiencing 
due to the diagnosis of breast cancer [29]. There is also relatively little known about the psychological impact of BLM or CPM. The few studies performed, to date, all but one of which was retrospective in nature, have reported high levels of satisfaction with CPM and no adverse effects on health-related quality of life (HRQL) [30-32].

To summarize, recent advances in the technology of genetic testing for breast cancer open the possibility of offering women with a suspected hereditary form of the disease the opportunity to undergo RGCT in the period of time between receiving the diagnosis and undergoing primary treatment. For those high-risk women who opt for direct BLM or delayed CPM, there are clear advantages in terms of reduction in the risk of contralateral disease, although an improvement in survival has not yet been convincingly demonstrated [20,22]. Women who choose for (bilateral) mastectomy can also avoid having to undergo radiotherapy. This, in turn, can improve the results of breast reconstruction [33]. However, there are insufficient data available on the impact of RGCT, when offered routinely to high-risk women, on medical decision-making, and there is relatively little known about the impact of RGCT on cancer-specific distress, treatment satisfaction, and HRQL.

\section{Objectives and research hypotheses}

This study is evaluating the behavioral and psychosocial effects of the routine offer of RGCT to newly diagnosed primary breast cancer patients who meet criteria for being at-risk of having a $B R C A 1$ or $B R C A 2$ gene mutation. RGCT is being offered to women shortly after diagnosis, prior to surgery. The comparison group is composed of women who receive usual care (UC), in which RGCT is available but is rarely recommended or requested.

The specific research hypotheses are:

1. A significantly greater percentage of women in the RGCT group as compared to the UC group will undergo a direct bilateral mastectomy (BLM).

2. A significantly greater percentage of women in the RGCT group as compared to the UC group will undergo a delayed prophylactic contralateral mastectomy (CPM).

3. Women in the RGCT group will report significantly lower levels of perceived cancer risk, cancer worries, and cancer-related distress at 12 month follow-up than women in the UC group.

4. Women in the RGCT will have significantly higher levels of knowledge of genetic issues in breast cancer, and higher levels of decisional satisfaction than women in the UC group.

5. Following from hypotheses 1 and 2, women in the RGCT group will report significantly more problems with body image and sexuality than those in the UC group. No significant differences will be observed between the RGCT and the UC groups on other HRQL outcomes.

\section{Methods/Design}

This is a multicenter, randomized, controlled trial in which patients are randomized to RGCT or to UC on a 2:1 basis. The primary clinical outcomes include: the uptake of direct BLM or of delayed CPM. Data on surgical outcomes will be abstracted from the medical records. This protocol follows the CONSORT guidelines [34].

Psychosocial outcomes include: perceived risk for ipsilateral and contralateral breast cancer and for ovarian cancer, cancer-related worry and distress; knowledge of genetic aspects of breast cancer; decisional satisfaction; and HRQL. The study also is evaluating women's experience of and satisfaction with RGCT (i.e., the timing and quality of the services provided, the perceived impact on treatment decisions, the perceived need for additional psychosocial support, etc.), and the surgeons' experience with RGCT. Standardized questionnaires are administered at study entry (prior to randomization), and at 6 month and 12 month follow-up (see figure 1). The institutional review boards of all participating hospitals have approved the study. The study is registered at the Netherlands Trial Register (NTR1493) and ClinicalTrials.gov (NCT00783822).

\section{Participants}

The study sample will be composed of 255 women with a clinically confirmed, newly diagnosed primary breast cancer or ductal carcinoma in situ (DCIS) who meet at least one of the criteria for referral for genetic counseling and DNA analysis according to the Dutch Institute for Healthcare Improvement (CBO). These criteria are: (1) age at time of breast cancer diagnosis less than 35 years; (2) previous history of cancer in the contralateral breast, with the first breast cancer diagnosis at less than 50 years of age; (3) previous personal history of ovarian cancer; (4) a family history of ovarian cancer; (5) a first degree male relative with breast cancer; (6) breast cancer diagnosed under the age of 50 years, with a first degree relative diagnosed with breast cancer under the age of 50 years; (7) breast cancer diagnosed under the age of 50 years, with a relative with prostate cancer diagnosed under the age of 60 years; (8) breast cancer, with two or more relatives from the same side of the family diagnosed with breast cancer, where at least one family member (either the patient or a relative) was diagnosed under the age of 50 years; or (9) a proven $B R C A 1 / 2$ mutation in the family. Women who meet one or more of these criteria are considered to have a $10 \%$ or greater chance of having a BRCA $1 / 2$ gene mutation $[35,36]$. 


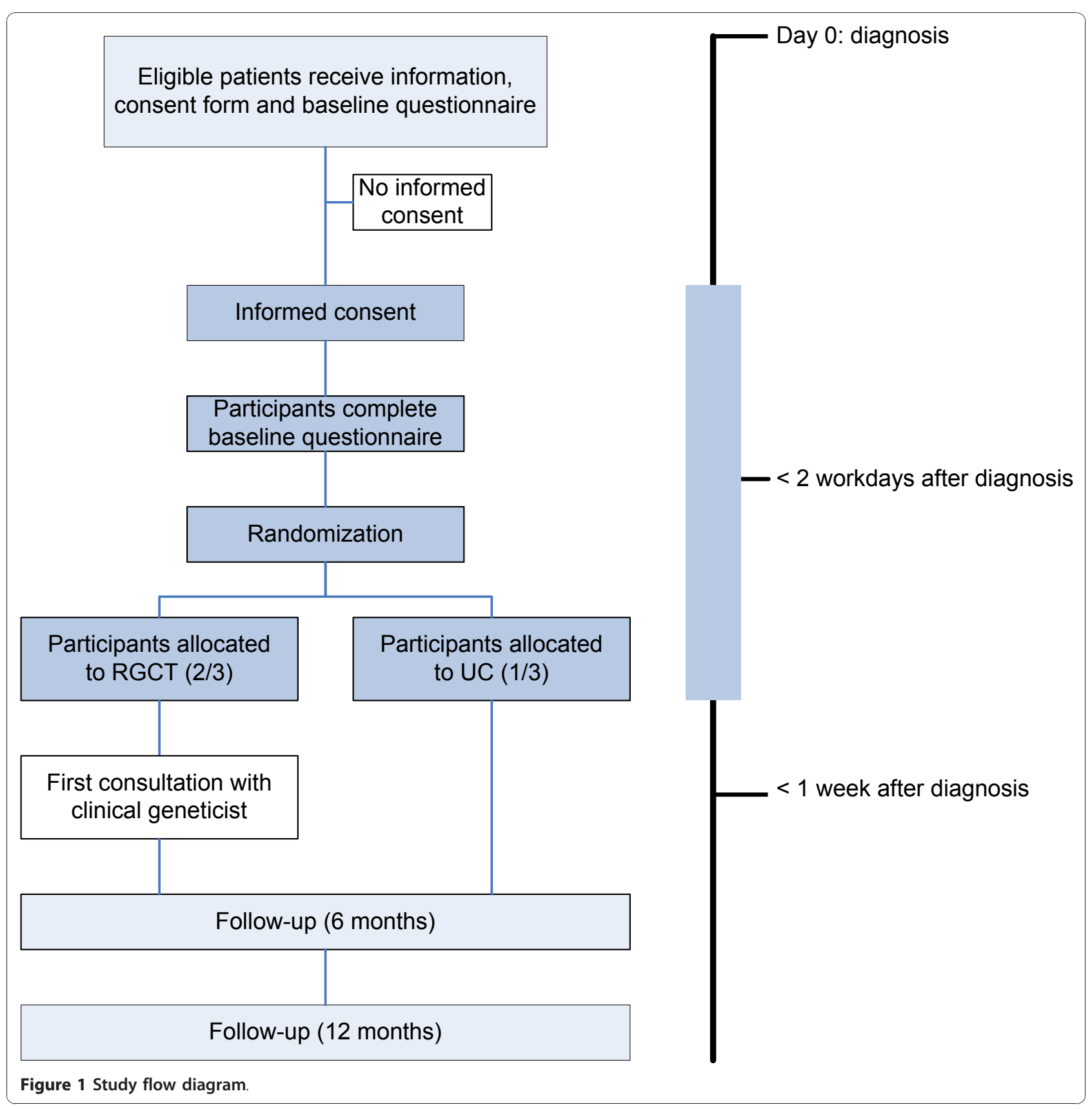

Women are excluded from the study if they are younger than 18 years of age, lack basic fluency in the Dutch language, are incapable of understanding informed consent, or are diagnosed with a breast cancer recurrence or with metastastic disease. The patients are being recruited from 12 hospitals in the Amsterdam and Utrecht regions of the Netherlands.

\section{Recruitment and randomization}

Patient recruitment began in November 2008, following approval by the ethical review committees of the participating hospitals. Participating surgeons make use of an 11-item checklist to determine patient eligibility. All patients who meet the study inclusion criteria are informed by the surgeon or nurse practitioner about the study, and are given an envelope containing an information letter, a consent form and the baseline questionnaire. Eligible patients receive a phone call by a member of the research team within a few days, in order to carry out the informed consent procedures and to administer the baseline questionnaire to consenting patients. Patients are then randomized to the RGCT or the UC 
group in a 2:1 ratio. The computerized randomization is stratified per hospital and blocked per 9 cases [37]. These 12 random allocation sequences are generated by an independent individual, are stored in computer files, and remain unknown to the researchers until the patient is randomized. The participant as well as the treating surgeon or nurse practitioner is informed about the randomization outcome. The researchers are blinded to randomization outcome at the time of the baseline assessments, but not at the follow-up assessments. This is due to the fact that the researchers are responsible for arranging appointments with the genetic counselor for those women assigned to the RGCT arm of the study.

\section{Intervention}

Women in the RGCT group receive an appointment with a clinical geneticist or genetic counselor within one week following randomization, either at the Family Cancer Clinic of the Netherlands Cancer Institute/ Antoni van Leeuwenhoek Hospital or at the Department of Medical Genetics of the University Medical Centre Utrecht. Those patients who decline to undergo RGCT are given the opportunity to receive genetic counseling and testing at a later time.

While the standard steps involved in genetic counseling are followed, the process is accelerated when necessary. All patients are asked to complete a standard, detailed family history form in order to draw a three-generation pedigree. Where possible, confirmation of the (age at) diagnosis of the affected family members is confirmed via medical record audits following required informed consent procedures. At the time of the first consultation with the clinical geneticist, the urgency of the steps to be taken are discussed and a decision about DNA testing is made. If the patient agrees, a blood sample for testing for mutations in the BRCA1 and BRCA2 genes can be taken on the same day. For women whose test result will not be of immediate consequence for their choice of treatment, the timing of the DNA testing does not need to be accelerated (i.e., DNA test results will be made available within 4 months). Examples are women who, from a medical point of view, cannot opt for breast conserving therapy and have already had a contralateral mastectomy, women who do not wish to take immediate secondary preventive measures, or women whose family history provides them with sufficient reasons to undergo bilateral treatment regardless of whether a mutation can be found.

Where it is anticipated that the DNA test results could influence treatment decisions, a fast-track procedure is used and the results are made available within 3 to 6 weeks. From a medical point of view, this timeframe is sufficiently short to inform patients and clinicians about the results before definite treatment decisions have to be made.

The number of contacts between the patient and the clinical geneticist prior to surgery depends on the complexity of each individual case. For women who choose not to undergo DNA testing, this may be limited to a single session. For women who undergo DNA testing, at least one additional session is held in order to discuss the DNA test results. All results of the RGCT are forwarded to the treating surgeon, and consultation between the clinical geneticist and surgeon takes place prior to and following the patient's first appointment with the clinical geneticist.

Psychosocial support is offered routinely to all women who opt for rapid DNA testing, BRCA1/2 carriers and to all women who are considering undergoing BLM regardless of whether they have undergone DNA testing. Where appropriate, referrals are made to mental health caregivers in the hospital. The need for and uptake of more intensive psychosocial care during subsequent treatment are being assessed as part of the study.

Women in the UC condition receive standard advice and care from their treating surgeon. In relation to the possible hereditary nature of their disease, this typically involves discussion of the family history and of appropriate surgical options. In some cases, patients may be referred for genetic counseling or may self-refer. However, in current practice, this occurs rarely during the pre-surgery period [38,39].

\section{Study measures}

\section{Sociodemographic and clinical data}

The patients' age, education, marital status, ethnic background, work status and general health status are obtained via the baseline questionnaire. Data on family pedigree and genetic risk status are obtained via a questionnaire. Clinical data, including diagnosis, tumor characteristics and treatment history (surgical treatment, surgical complications, breast reconstruction, radiotherapy, adjuvant chemotherapy or hormonal therapy) are obtained via both questionnaire and medical record audit. Results of the genetic counseling and testing, including genetic test results, are obtained from the records of the participating departments of clinical genetics.

\section{Choice of surgical procedure}

The patients' definitive surgical treatment decision is determined via medical record audit. Via questionnaires women are asked to report the factors motivating their choice of treatment.

Risk perception is assessed with 4 items adapted from previous studies [40-42] that inquire about current perceived risk of recurrent or contralateral breast cancer (all questionnaires), of ovarian cancer, and of the 
possibility of having hereditary breast cancer (follow-up questionnaires). Women are asked to rate on a 5-point scale how likely they think it is that they will develop cancer again, and to rate their perceived risk on a continuous scale from $0 \%$ to $100 \%$.

Cancer worries are assessed with 8 items, 6 of which are adapted from previous work by Watson [40,43], that measure the frequency of cancer-related worries, their impact on mood, and their impact on daily functioning.

The Hospital Anxiety and Depression Scale (HADS) [44] is used to assess psychological distress. The HADS contains 14 items. Both a total score and separate scores for anxiety and depression can be calculated. The HADS has been validated for use in the Dutch population, showing good psychometric properties, with Cronbach's alphas for both the anxiety and depression scales $>0.70$ [45-47].

Cancer-specific distress is assessed with the Impact of Events Scale (IES), a 15-item Likert-scale organized into 2 subscales: intrusive thoughts and feelings, and avoidance of thoughts and feelings related to the stressful situation. In this case, the stressful situation is the diagnosis of breast cancer [48]. The IES has high levels of internal consistency (alpha's above 0.80) and has been translated and validated for use in the Dutch setting [49].

Satisfaction with decision-making is assessed with the Satisfaction with Decision Scale (SWD) [50] and the Decisional Conflict Scale [51,52]. The 6-item SWD-scale can be adapted to any medical decision and, in this case, refers to the choice of surgical treatment. The scale has high internal consistency reliability (alpha $=0.86)$ [50]. The 16-item Decisional Conflict Scale contains three subscales: 'Uncertainty', 'Factors contributing' and 'Effective decision making'. The scale had high internal consistency reliability (alpha of the three subscales ranges from 0.75-0.82 in the Dutch version).

Knowledge of breast cancer and its genetic aspects is assessed with a 7-item, true-false-don't know questionnaire adapted from Claes et al. [14,53].

Health-related quality of life is assessed with the EORTC QLQ-C30 [54] and the EORTC breast cancer module, the QLQ-BR23 [55]. The QLQ-C30 includes 5 functional scales, 3 symptom scales, and a number of single item symptom measures. It is designed for use with a broad range of cancer patient populations. The QLQ-BR23 assesses breast cancer-specific symptoms, treatment side-effects, body image, sexuality and future perspective. Both questionnaires have been used extensively in studies of women with breast cancer, and exhibit good levels of reliability (alpha coefficients between 0.70 and 0.85 ) and construct validity.

\section{Process-related variables}

Perceived influence of the surgeon on treatment choice is assessed with a series of questions adapted from Schwartz et al. [24]. Women in the RGCT arm of the study are asked a series of study-specific questions about their experience and satisfaction with RGCT, and their perceived need for additional psychosocial care. Psychosocial care actually received is also being determined from the medical records and via self-report. The content of the professional psychosocial support received is also being assessed.

\section{Sample size}

The sample size calculations are based primarily on the type of surgery chosen, and specifically on the uptake of bilateral mastectomy. With a total sample of 255 women (170 in the RGCT arm and 85 in the UC arm), the study will have $80 \%$ power to detect a difference of $18 \%$ versus $5 \%$ in the uptake of bilateral mastectomy, with the p-value set at 0.05 . The sample size ratio of 2:1 was chosen to ensure that the RGCT sample is sufficiently large to obtain stable estimates of bilateral mastectomy and delayed prophylactic contralateral mastectomy uptake among $B R C A 1 / 2$ carriers, and to allow for secondary analyses (e.g., to examine predictors of DNA testing uptake). The percentages indicated above are based on the following assumptions: (1) based on the participating hospitals' experiences in the previous three years, $5 \%$ of the women in the UC arm are expected to choose bilateral mastectomy; (2) in the RGCT arm, it is expected that $20 \%$ will test positive for a $B R C A 1$ or BRCA2 mutation, of whom, on average, $50 \%$ will opt for a bilateral mastectomy. Of the remaining $80 \%$ of women in the RGCT arm, we expect a $10 \%$ uptake of bilateral mastectomy. For the remaining, primarily self-report outcomes (e.g., cancer worries and cancer-specific distress, decisional satisfaction, HRQL), the sample of 255 participants is more than sufficient to detect a 0.5 standard deviation betweengroup difference in mean scores. Based on data obtained from the cancer registries of the Integral Cancer Centers of Amsterdam and Middle Netherlands, and on data provided by the participating hospitals, it is estimated that there will be a total of 2550 newly diagnosed breast cancer patients during the recruitment period. Approximately $15 \%$ of these women is expected to be eligible for participation. Based on prior experience with recruitment of patients into similar studies, we expect an $80 \%$ response rate. This results in an expected $\mathrm{N}$ of 306 patients. This allows for an attrition rate of $17 \%$, while retaining 255 women for the primary analysis. 


\section{Statistical analyses}

Analyses will first be performed to evaluate the comparability of the RGCT and the UC groups at study entry in terms of sociodemographic and clinical characteristics. Student's t-test or appropriate non-parametric statistics will be used, depending on the level of measurement. If the groups are not comparable on one or more background variables, those variables will be employed routinely as covariates in subsequent analyses. Between group differences in choice of surgery will be tested using the chi-square statistic or, if statistical adjustment is required for covariates, multiple logistic regression analysis. Analysis of (co)variance will be employed to assess group differences at 6 and 12 month follow-up in risk perception, psychological distress, knowledge, decisional satisfaction, and HRQL. Where appropriate, sociodemographic and clinical background variables, as well as baseline scores on the outcomes of interest, will be used as covariates. Effect sizes will be calculated using standard statistical procedures. Supplementary, descriptive analyses (both quantitative and qualitative) will be used for reporting the patients' experiences with RGCT. All primary analyses will, to as great an extent as possible, be conducted on an intention-to-treat basis. That is, all women in the RGCT group will be included in that group in the analyses, regardless of whether they actually carried through with RGCT. Supplementary analyses will be undertaken to examine sociodemographic, clinical and psychosocial factors associated significantly with (non-) attendance at the RGCT and uptake of BLM.

\section{Discussion}

It is common practice to refer breast cancer patients with suspected hereditary breast cancer for genetic counseling and testing after their initial treatment has been completed [38]. Women found to have a mutation in the $B R C A 1$ or $B R C A 2$ gene may opt for additional preventive surgery following their initial surgical treatment. A complicating factor in delaying genetic counseling and testing until after the completion of primary treatment is that, when that treatment includes radiotherapy, additional, preventive surgical procedures (e.g., mastectomy with breast reconstruction) may be quite challenging for the plastic surgeon [33]. By offering genetic counseling and testing in the period between breast cancer diagnosis and initial surgical treatment, it is possible to incorporate the results of those procedures into treatment decision-making. It is important to note that genetic counseling, whether done prior to or following primary treatment, is non-directive in nature. The intent is to provide women with information about the possible hereditary basis of their disease, so that they can make informed choices regarding primary surgical and adjuvant treatment, as well as possible preventive surgery. However, little information is currently available on the benefits and potential problems associated with RGCT from the patients' perspective. It is important to determine these effects now, as it is anticipated that RGCT will be increasingly common place, as non-commercial genetic labs gear up to be able to generate DNA test results in only a matter of weeks. Moreover, rapid genetic counseling, in and of itself, may influence treatment decisions. It should be noted that the results of RGCT are not only expected to influence the choice of surgical treatment, but may also have an impact on chemotherapy options as well. Specific chemotherapeutic agents such as PARP-inhibitors are being developed that have antitumor activity in $B R C A$ associated cancer [56].

\section{Methodological considerations}

The major methodological strength of this study is the use a randomized controlled trial design which will allow a rigorous test of the effects of RGCT with optimal internal validity. The relatively large sample size and the use of primarily standardized measures represent additional strengths of the study. Finally, the trial's multicenter nature should increase the external validity or generalizability of the study findings.

A limitation of this study is the relatively short period of follow-up (12 months). While this is sufficient for examining the effect of RGCT on primary treatment choice and on short term psychosocial outcomes, it does not permit longer term follow-up on these latter outcomes.

\section{Conclusion}

This study is expected to provide important information on the impact of RGCT among newly diagnosed breast cancer patients on the choice of surgical treatment and on psychosocial well-being. Since RGCT is anticipated to become common practice in the future, the results of this study can contribute to improving the quality of multidisciplinary breast cancer care.

\footnotetext{
Acknowledgements

Participating surgeons: EJTh Rutgers, H Oldenburg, BC Vrouenraets, PJ Borgstein, H Rijna, JJ Huisman, R van Hillegersberg, AJ Witkamp, T van Dalen, EBM Theunissen, B van Ooijen, M de Roos, JP Vente, WH Bouma. Participating hospitals: Antoni van Leeuwenhoek Hospital, Amsterdam; Sint Lucas Andreas Hospital, Amsterdam; Onze Lieve Vrouwe Hospital, Amsterdam, Kennemer Gasthuis, Haarlem; Tergooi Hospital, Blaricum/ Hilversum; University Medical Centre Utrecht; Diakonessenhuis, Utrecht; Sint Antonius Hospital, Nieuwegein/Utrecht; Meander Medical Centre, Amersfoort; Rivierenland Hospital, Tiel; Zuwe Hofpoort Hospital, Woerden; Gelre Hospital, Apeldoorn.

Other collaborators: Titia Brouwer, University Medical Centre Utrecht, the Netherlands and Marc Schwartz, Lombardi Comprehensive Cancer Center, Georgetown University Medical Center, Washington DC, USA

Research assistants: Marianne Kuenen, Jacoline Melis
} 
Sponsors: This study is supported by a grant from the NutsOHRA Foundation (grant number SNO-T-0701-95).

\section{Author details}

'Division of Psychosocial Research and Epidemiology, The Netherlands Cancer Institute, PO Box 90203, 1006 BE Amsterdam, The Netherlands. ${ }^{2}$ Division of Medical Genetics, University Medical Center Utrecht, PO Box 85090, 3508 AB Utrecht, The Netherlands. ${ }^{3}$ Division of Diagnostic Oncology, The Netherlands Cancer Institute, PO Box 90203, 1006 BE Amsterdam, The Netherlands. ${ }^{4}$ Division of Medical Oncology, The Netherlands Cancer Institute, PO Box 90203, 1006 BE Amsterdam, The Netherlands. ${ }^{5}$ Oncological Sciences Department, Mount Sinai School of Medicine, Icahn Medical Institute, 1425 Madison Avenue, New York, NY 10029, USA. ${ }^{6}$ Division of Surgery, University Medical Center Utrecht, PO Box 85500, 3508 GA Utrecht, The Netherlands. ${ }^{7}$ Division of Surgical Oncology, The Netherlands Cancer Institute, PO Box 90203, 1006 BE Amsterdam, The Netherlands.

\section{Authors' contributions}

NKA, MGEMA and SV are the principal investigators of this study. MRW is the doctoral student on this study, and generated the first draft of this manuscript based on the study protocol. EMAB, DEEH, and HBV contributed to the development of the study protocol. EJThR and RvH are the lead surgeons. FH and RBvdL are the collaborating molecular geneticists. All authors approved the final version of the manuscript.

\section{Competing interests}

NutsOhra Foundation, a charitable fund linked to the private insurance company NutsOhra, has financially supported this study. There are no other competing interests.

Received: 30 March 2010 Accepted: 10 January 2011

Published: 10 January 2011

\section{References}

1. Turnbull C, Hodgson S: Genetic predisposition to cancer. Clin Med 2005, 5:491-498

2. Vasen HF, Tesfay E, Boonstra H, Mourits MJ, Rutgers E, Verheyen R, Oosterwijk J, Beex L: Early detection of breast and ovarian cancer in families with BRCA mutations. Eur J Cancer 2005, 41:549-554.

3. Evans DG, Lalloo F, Hopwood P, Maurice A, Baildam A, Brain A, Barr L, Howell A: Surgical decisions made by 158 women with hereditary breast cancer aged $<50$ years. Eur J Surg Oncol 2005, 31:1112-1118.

4. van der Hout AH, van den Ouweland AM, van der Luijt RB, Gille HJ, Bodmer D, Bruggenwirth $\mathrm{H}$, Mulder IM, van der Vlies $\mathrm{P}$, Elfferich $\mathrm{P}$, Huisman MT, ten Berge AM, Kromosoeto J, Jansen RP, van Zon PH, Vriesman T, Arts N, Lange MB, Oosterwijk JC, Meijers-Heijboer $\mathrm{H}_{\text {, }}$ Ausems MG, Hoogerbrugge N, Verhoef S, Halley DJ, Vos YJ, Hogervorst F, Ligtenberg M, Hofstra RM: A DGGE system for comprehensive mutation screening of BRCA1 and BRCA2: application in a Dutch cancer clinic setting. Hum Mutat 2006, 27:654-666.

5. Eccles DM: Identification of personal risk of breast cancer: genetics. Breast Cancer Res 2008, 10(Suppl 4):S12.

6. Easton DF, Ford D, Bishop DT: Breast and ovarian cancer incidence in BRCA1-mutation carriers. Breast Cancer Linkage Consortium. Am J Hum Genet 1995, 56:265-271.

7. Narod SA, Offit K: Prevention and management of hereditary breast cancer. J Clin Oncol 2005, 23:1656-1663.

8. Metcalfe K, Lynch HT, Ghadirian P, Tung N, Olivotto I, Warner E, Olopade OI, Eisen A, Weber B, McLennan J, Sun P, Foulkes WD, Narod SA: Contralateral breast cancer in BRCA1 and BRCA2 mutation carriers. J Clin Oncol 2004, 22:2328-2335.

9. Graeser MK, Engel C, Rhiem K, Gadzicki D, Bick U, Kast K, Froster UG, Schlehe B, Bechtold A, Arnold N, Preisler-Adams S, Nestle-Kraemling C, Zaino M, Loeffler M, Kiechle M, Meindl A, Varga D, Schmutzler RK. Contralateral breast cancer risk in BRCA1 and BRCA2 mutation carriers. J Clin Oncol 2009, 27:5887-5892.

10. Schwartz MD, Peshkin BN, Hughes C, Main D, Isaacs C, Lerman C: Impact of BRCA1/BRCA2 mutation testing on psychologic distress in a clinic-based sample. J Clin Oncol 2002, 20:514-520.
11. Braithwaite D, Emery J, Walter F, Prevost AT, Sutton S: Psychological impact of genetic counseling for familial cancer: a systematic review and meta-analysis. J Natl Cancer Inst 2004, 96:122-133.

12. Peshkin BN, DeMarco TA, Brogan BM, Lerman C, Isaacs C: BRCA1/2 testing: complex themes in result interpretation. J Clin Oncol 2001, 19:2555-2565.

13. Peshkin BN, Isaacs C: Evaluation and management of women with BRCA1/2 mutations. Oncology (Williston Park) 2005, 19:1451-1459.

14. Pieterse AH, Ausems MG, Van Dulmen AM, Beemer FA, Bensing JM: Initial cancer genetic counseling consultation: change in counselees' cognitions and anxiety, and association with addressing their needs and preferences. Am J Med Genet A 2005, 137:27-35.

15. Rantala J, Platten U, Lindgren G, Nilsson B, Arver B, Lindblom A, Brandberg Y: Risk perception after genetic counseling in patients with increased risk of cancer. Hered Cancer Clin Pract 2009, 7:15.

16. Roshanai AH, Rosenquist R, Lampic C, Nordin K: Does enhanced information at cancer genetic counseling improve counselees' knowledge, risk perception, satisfaction and negotiation of information to at-risk relatives?-a randomized study. Acta Oncol 2009, 48:999-1009.

17. Meijers-Heijboer H, Brekelmans CT, Menke-Pluymers M, Seynaeve C, Baalbergen A, Burger C, Crepin E, van den Ouweland AW, van Geel B, Klijn JG: Use of genetic testing and prophylactic mastectomy and oophorectomy in women with breast or ovarian cancer from families with a BRCA1 or BRCA2 mutation. J Clin Oncol 2003, 21:1675-1681.

18. Gronau KA, Semple JL: A guide to establishing the risk for breast cancer in the plastic surgery patient. Ann Plast Surg 2000, 45:554-559.

19. Mitchell G, Ardern-Jones A, Kissin Mchir M, Taylor R, Eeles RA: A paradox: urgent BRCA genetic testing. Fam Cancer 2001, 1:25-29.

20. van Sprundel TC, Schmidt MK, Rookus MA, Brohet R, van Asperen CJ, Rutgers EJ, Van't Veer LJ, Tollenaar RA: Risk reduction of contralateral breast cancer and survival after contralateral prophylactic mastectomy in BRCA1 or BRCA2 mutation carriers. Br J Cancer 2005, 93:287-292.

21. McDonnell SK, Schaid DJ, Myers JL, Grant CS, Donohue JH, Woods JE, Frost MH, Johnson JL, Sitta DL, Slezak JM, Crotty TB, Jenkins RB, Sellers TA, Hartmann LC: Efficacy of contralateral prophylactic mastectomy in women with a personal and family history of breast cancer. J Clin Oncol 2001, 19:3938-3943.

22. Herrinton LJ, Barlow WE, Yu O, Geiger AM, Elmore JG, Barton MB, Harris EL, Rolnick S, Pardee R, Husson G, Macedo A, Fletcher SW: Efficacy of prophylactic mastectomy in women with unilateral breast cancer: a cancer research network project. J Clin Oncol 2005, 23:4275-4286.

23. Kurian AW, Sigal BM, Plevritis SK: Survival analysis of cancer risk reduction strategies for BRCA1/2 mutation carriers. J Clin Oncol 2010, 28:222-231.

24. Schwartz MD, Lerman C, Brogan B, Peshkin BN, Isaacs C, DeMarco T, Halbert $\mathrm{CH}$, Pennanen M, Finch C: Utilization of BRCA1/BRCA2 mutation testing in newly diagnosed breast cancer patients. Cancer Epidemiol Biomarkers Prev 2005, 14:1003-1007.

25. Schwartz MD, Lerman C, Brogan B, Peshkin BN, Halbert CH, DeMarco T, Lawrence W, Main D, Finch C, Magnant C, Pennanen M, Tsangaris T, Willey $S$, Isaacs C: Impact of BRCA1/BRCA2 counseling and testing on newly diagnosed breast cancer patients. J Clin Oncol 2004, 22:1823-1829.

26. Schlich-Bakker KJ, ten Kroode HF, Ausems MG: A literature review of the psychological impact of genetic testing on breast cancer patients. Patient Educ Couns 2006, 62:13-20.

27. Schlich-Bakker KJ, Warlam-Rodenhuis CC, van Echtelt J, van den Bout J, Ausems MG, ten Kroode HF: Short term psychological distress in patients actively approached for genetic counselling after diagnosis of breast cancer. Eur J Cancer 2006, 42:2722-2728.

28. Schlich-Bakker KJ, Ausems MG, Schipper M, ten Kroode HF, WarlamRodenhuis CC, van den Bout J: BRCA1/2 mutation testing in breast cancer patients: a prospective study of the long-term psychological impact of approach during adjuvant radiotherapy. Breast Cancer Res Treat 2008, 109:507-514.

29. Hahn DEE, Bleiker EMA, Aaronson NK, Valdimarsdottir HB, Verhoef S: Experiences with rapid genetic counseling and testing in newly diagnosed breast cancer patients [abstract]. Psychooncology 2006, 15: S261.

30. Frost MH, Slezak JM, Tran NV, Williams Cl, Johnson JL, Woods JE, Petty PM, Donohue JH, Grant CS, Sloan JA, Sellers TA, Hartmann LC: Satisfaction after contralateral prophylactic mastectomy: the significance of mastectomy type, reconstructive complications, and body appearance. J Clin Oncol 2005, 23:7849-7856. 
31. Geiger AM, West CN, Nekhlyudov L, Herrinton LJ, Liu IL, Altschuler A, Rolnick SJ, Harris EL, Greene SM, Elmore JG, Emmons KM, Fletcher SW: Contentment with quality of life among breast cancer survivors with and without contralateral prophylactic mastectomy. J Clin Oncol 2006, 24:1350-1356

32. Tercyak KP, Peshkin BN, Brogan BM, DeMarco T, Pennanen MF, Willey SC, Magnant CM, Rogers S, Isaacs C, Schwartz MD: Quality of life after contralateral prophylactic mastectomy in newly diagnosed high-risk breast cancer patients who underwent BRCA1/2 gene testing. J Clin Oncol 2007, 25:285-291.

33. Reavey P, McCarthy CM: Update on breast reconstruction in breast cancer. Curr Opin Obstet Gynecol 2008, 20:61-67.

34. Moher D, Schulz KF, Altman DG: The CONSORT statement: revised recommendations for improving the quality of reports of parallel group randomized trials. BMC Med Res Methodol 2001, 1:2.

35. Couch FJ, DeShano ML, Blackwood MA, Calzone K, Stopfer J, Campeau L, Ganguly A, Rebbeck T, Weber BL: BRCA1 mutations in women attending clinics that evaluate the risk of breast cancer. N Engl J Med 1997, 336:1409-1415.

36. The Dutch Association of Comprehensive Cancer Centres - Breast Cancer Guideline 1.1. [http://www.oncoline.nl].

37. Piantadosi S: Clinical Trials: A Methodologic Perspective New York: John Wiley \& Sons; 1997.

38. Van Riel E, Warlam-Rodenhuis CC, Verhoef S, Rutgers EJ, Ausems MG: BRCA testing of breast cancer patients: medical specialists' referral patterns, knowledge and attitudes to genetic testing. Eur J Cancer Care (Engl) 2010, 19:369-376.

39. Ardern-Jones A, Kenen R, Eeles R: Too much, too soon? Patients and health professionals' views concerning the impact of genetic testing at the time of breast cancer diagnosis in women under the age of 40 . Eur $\mathrm{J}$ Cancer Care (Engl) 2005, 14:272-281.

40. Lerman C, Lustbader E, Rimer B, Daly M, Miller S, Sands C, Balshem A: Effects of individualized breast cancer risk counseling: a randomized trial. J Natl Cancer Inst 1995, 87:286-292.

41. Madalinska JB, Hollenstein J, Bleiker E, van Beurden M, Valdimarsdottir HB, Massuger LF, Gaarenstroom KN, Mourits MJ, Verheijen RH, van Dorst EB, van der Putten $H$, van der Velden K, Boonstra H, Aaronson NK: Quality-of-life effects of prophylactic salpingo-oophorectomy versus gynecologic screening among women at increased risk of hereditary ovarian cancer. J Clin Oncol 2005, 23:6890-6898

42. Valdimarsdottir HB, Bovbjerg DH, Dash KM, Holland JC, Osborne MP, Miller DG: Psychological distress in women with a familial risk of breast cancer. Psychooncology 1995, 4:133-141.

43. Watson M, Duvivier V, Wade Walsh M, Ashley S, Davidson J, Papaikonomou M, Murday V, Sacks N, Eeles R: Family history of breast cancer: what do women understand and recall about their genetic risk? J Med Genet 1998, 35:731-738.

44. Zigmond AS, Snaith RP: The hospital anxiety and depression scale. Acta Psychiatr Scand 1983, 67:361-370.

45. de Bock GH, Bonnema J, Zwaan RE, van de Velde CJ, Kievit J, Stiggelbout AM: Patient's needs and preferences in routine follow-up after treatment for breast cancer. Br J Cancer 2004, 90:1144-1150.

46. Turner J, Kelly B, Swanson C, Allison R, Wetzig N: Psychosocial impact of newly diagnosed advanced breast cancer. Psychooncology 2005 14:396-407.

47. Spinhoven P, Ormel J, Sloekers PP, Kempen Gl, Speckens AE, Van Hemert AM: A validation study of the Hospital Anxiety and Depression Scale (HADS) in different groups of Dutch subjects. Psychol Med 1997, 27:363-370

48. Horowitz M, Wilner N, Alvarez W: Impact of Event Scale: a measure of subjective stress. Psychosom Med 1979, 41:209-218.

49. Brom D, Kleber RJ: De Schok Verwerkingslijst [The Impact of Event Scale]. Ned Tijdschr Psych 1985, 41:164-168.

50. Holmes-Rovner M, Kroll J, Schmitt N, Rovner DR, Breer ML, Rothert ML, Padonu G, Talarczyk G: Patient satisfaction with health care decisions: the satisfaction with decision scale. Med Decis Making 1996, 16:58-64.

51. O'Connor AM: Validation of a decisional conflict scale. Med Decis Making 1995, 15:25-30.

52. Koedoot N, Molenaar S, Oosterveld P, Bakker P, de Graeff A, Nooy M, Varekamp I, de Haes $\mathrm{H}$ : The decisional conflict scale: further validation in two samples of Dutch oncology patients. Patient Educ Couns 2001, 45:187-193.

53. Claes E, Evers-Kiebooms G, Boogaerts A, Decruyenaere M, Denayer L, Legius $\mathrm{E}$ : Communication with close and distant relatives in the context of genetic testing for hereditary breast and ovarian cancer in cancer patients. Am J Med Genet A 2003, 116A:11-19.

54. Aaronson NK, Ahmedzai S, Bergman B, Bullinger M, Cull A, Duez NJ, Filiberti A, Flechtner H, Fleishman SB, de Haes JC: The European Organization for Research and Treatment of Cancer QLQ-C30: a qualityof-life instrument for use in international clinical trials in oncology. $\mathrm{J} \mathrm{Natl}$ Cancer Inst 1993, 85:365-376.

55. Sprangers MA, Groenvold M, Arraras JI, Franklin J, te Velde A, Muller M, Franzini L, Williams A, de Haes HC, Hopwood P, Cull A, Aaronson NK: The European Organization for Research and Treatment of Cancer breast cancer-specific quality-of-life questionnaire module: first results from a three-country field study. J Clin Oncol 1996, 14:2756-2768.

56. Fong PC, Boss DS, Yap TA, Tutt A, Wu P, Mergui-Roelvink M, Mortimer $P$, Swaisland H, Lau A, O'Connor MJ, Ashworth A, Carmichael J, Kaye SB, Schellens $J H$, de Bono JS: Inhibition of poly(ADP-ribose) polymerase in tumors from BRCA mutation carriers. N Engl J Med 2009, 361:123-134.

\section{Pre-publication history}

The pre-publication history for this paper can be accessed here: http://www.biomedcentral.com/1471-2407/11/6/prepub

\section{doi:10.1186/1471-2407-11-6}

Cite this article as: Wevers et al:: Behavioral and psychosocial effects of rapid genetic counseling and testing in newly diagnosed breast cancer patients: Design of a multicenter randomized clinical trial. BMC Cancer 2011 11:6

\section{Submit your next manuscript to BioMed Central and take full advantage of:}

- Convenient online submission

- Thorough peer review

- No space constraints or color figure charges

- Immediate publication on acceptance

- Inclusion in PubMed, CAS, Scopus and Google Scholar

- Research which is freely available for redistribution 